\title{
A Descriptive Analysis of the Possible Causes of the Inverse Audit Outcomes: Case of Supply Chain Management of the KwaZulu-Natal Province, South Africa
}

\author{
Sakhile Manyathi \\ Deputy Director: SCM Training, Department of National Treasury \\ Email: Sakhile.Manyathi@treasury.gov.za \\ Ferdinand Niyimbanira \\ Lecturer in Economics, Vaal University of Technology (VUT) \\ Email: ferdinandn@vut.ac.za
}

Doi:10.5901/mjss.2014.v5n16p82

\begin{abstract}
Determining the most quantitative possible root causes of the inverse audit reports, will discover whether inadequate training and compliance enforcement are among the top possible determinants of the inverse audit reports received by the KwaZuluNatal (KZN) Provincial Administration for the financial year 2007/2008. It is recommended that management consider building professional networking opportunities, identify opportunities for country-level networking and mentoring, as well as communities of practice related to procurement through supply chain management (SCM); engage existing professional associations (private and public sector) for example Chartered Institute of Purchasing and Supply. It is also recommended that segregation of duties among SCM practitioners will bring about efficiency in procurement practices. This implies that employees understand and see the need for the segregation of duties, as one of the elements with which to curb fraud and bring about efficiency in SCM operations, this was strongly agreed by 63 percent of the respondents. It is further recommended that there must be a review of current legislation that regulates Public Sector procurement. This infers that Public Sector procurement legislation does not address the needs of public procurement ultimately service delivery, a collective 59 percent of the respondents strongly agreed.
\end{abstract}

Keywords: Legislation, Supply Chain Management, Compliance, Service Delivery

\section{Introduction}

This paper reports on the results of the study, by analysing the findings from the survey undertaken in KZN, South Africa. According to Creswell (2009:189), data analysis may be defined as the breakdown and ordering of data into meaningful groups, plus the searching of patterns of relationships among these data groups. The questionnaire was analysed, using Microsoft Word and Microsoft Excel statistical software packages. Each response has been graphically represented according to the questionnaire. This allows for easy identification of problem areas that require attention by the Provincial Treasury as it is the custodian of all supply chain management processes, norms and standards for the province. It regulates all KZN provincial government departments in terms of legislation, prescripts, processes, and procedures regarding SCM.

Commencing with the demographic section of the questionnaire, responses were scrutinized in terms of their distribution and percentage responses, transferring the data into information across a range of categories, from demographic statistics, through to the specific variables of interest applicable to this study. A five point Likert scale was used to measure the output of each item answered by the respondents of the study.

\section{Literature Review}

\subsection{Theoretical framework}

Numerous theories have been used by researchers to understand why some supply chains succeed in creating value while others do not. Although perspectives of and prescription to SCM vary, a common idea among researchers is that competitive success for a strategic supply chain is contingent on management's ability to recognize changes in the 
competitive environment and then direct and coordinate action within and across organizations to utilize resources effectively and meet the demands of the environment (Stonebraker and Afifi, 2004). This is attributed to the contingency theory.

A second theory that helps explain how supply chains can create value is force field theory (Lewin, 1951). According to the Force field theory, the ability to scan the environment for the forces driving SCM, to identify the potential barriers (or resisting forces), and to implement bridges enables SCM actors to maintain competitive success in changing environments and markets. The contingency model is driven by technological innovation, management skills across departments and organizational functions, and integration vertically and horizontally across industry (Stonebraker and Afifi, 2004).

However, implementation of a successful supply chain may encounter resisting forces that include lack of SCM actor's support, inadequate measurement and information systems, and organizational culture. Thus, successful supply chains can create value contingent on their ability to overcome resisting forces through various mechanisms. Figure 1 shows a contingency framework for understanding SCM implementation.

Figure 1. A contingency framework for understanding supply chain implementation industry

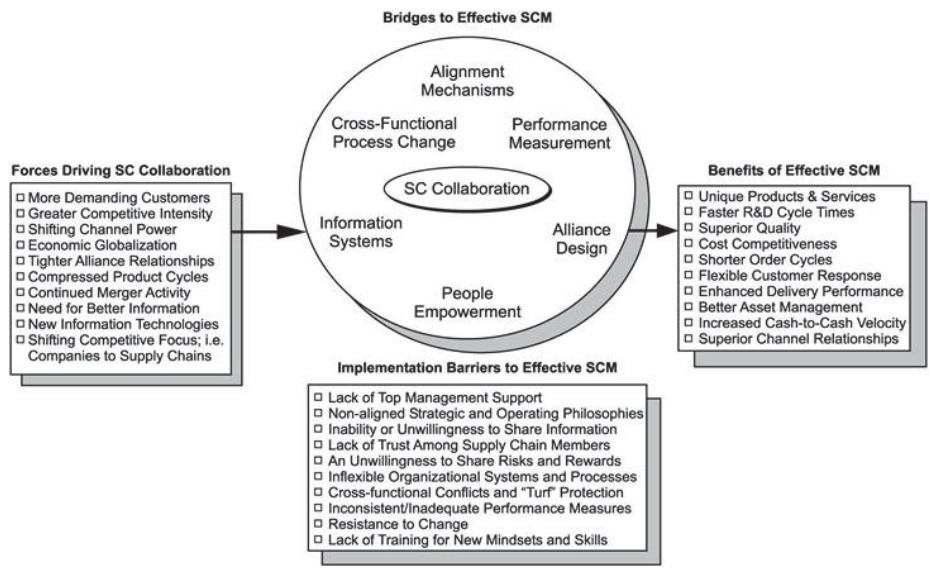

Source: Stonebraker and Afifi, 2004

\subsection{SCM in the Public Sector}

Public sector SCM is a concept that offers a reference framework for the composition of Public sector Supply Chains and multilevel networks. Actors in public sector supply chain comprise (1) private firms which receive orders from public sector agents, (2) accounting officers and (3) policy-makers. The SCM in the public sector not only concentrates on the question, which institutions cooperate in goods and services, but also how these enterprises are involved with enterprises operating at other levels. Thus, analyses of intra-network-relationships as well as analyses of inter -network-relationship are essentially necessary elements of the concept (Migiro and Ambe, 2008). SCM in the public sector differs from government sector-to-sector. In the health sector, for example, the focus may be more on logistics and the effective movement of goods and services in and out of hospitals whereas SCM in the education sector may focus on streamlining the chain through which teaching materials are delivered to students. The shape of the supply chain and the supply chain management processes employed will therefore vary considerably depending on a range of different (Migiro and Ambe, 2008).

Public supply chain may be inbound into the public sector that is an operational requirement for internal customers and may be outbound from the public sector to deliver wider organizational objectives to provide services for delivery to citizens, or a combination of both. Supply chain is inbound to the public sector where suppliers deliver goods and services into the public sector departments to support their operational objectives e.g. office furniture provision. While it is outbound from the public sector - directly supporting the needs of the public e.g. suppliers delivering training services for public sector funded projects.

For two decades now, the South African public sector supply chain has undergone transformation through the 
introduction of procurement reforms. The procurement reforms started in 1995 and were directed at two broad focus areas, namely the promotion of principles of good governance and the introduction of a preference system to address socio-economic objectives. The procurement reform processes were embedded in section 76(4) (C) of the Public Finance Management Act (PFMA) and the Preferential Procurement Policy Frame-work Act (Act No 5 of 2000) (PPPFA) (Migiro and Ambe, 2008).

To introduce and implement the reforms, the SCM unit at the National Treasury in 2001 completed a joint country procurement assessment review (CPAR) with the World Bank to assess procurement practices throughout the public sector. The CPAR identified certain deficiencies in practices relating to governance, interpretation and implementation of PPPFA and its associated regulations (National Treasury RSA, 2003:2). The deficiencies led the provincial treasuries, in conjunction with the national treasury, to vigorously embark on a reform initiative to introduce best procurement practices that are efficient and effective. Based on this, SCM was introduced in the South African public sector (Mkhize, 2004).

In the past, most of the focus in the departmental procurement process was devoted to meeting the requirements of the Tender Boards. However, Tender Boards have since for their procurement processes, within the Republic of South Africa been abolished and institutions have become responsible for their procurement, procurement framework published by the South African Government (Republic of South Africa, 2005). The framework emphasized the application of the SCM requirements. The requirements cover demand management, acquisition management, logistics management, disposal management, risk management and performance management as per figure 2

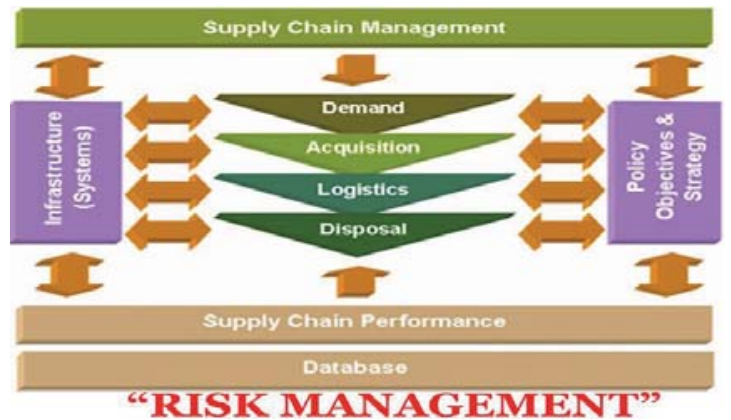

Figure 2. Framework of the South African Public Sector Supply Chain Management

Source: Republic of South Africa, 2005

\subsubsection{Demand management}

Need assessment (demand) precedes the implementation of SCM. The objective is to ensure that goods and services delivered comply with specifications of the identified needs. It also ensures that resources required to fulfill needs identified in the needs assessment reports for the departments and for the municipalities in the IDP and this is used to make sure that goods, services and works are delivered at the correct time, price and place and that the quantity and quality satisfies the needs (Migiro and Ambe, 2008).

\subsubsection{Acquisition management}

Acquisition management is the management of procurement. Each public entity decides on the manner in which the market should be approached, establishes the total cost of ownership of assets, ensures that bid documentations are complete including evaluation criteria, evaluates bids in accordance with published criteria and ensures that proper contract documents are signed (Republic of South Africa. 2003).

\subsubsection{Logistics management}

Logistics is the process of strategically managing acquisition, movement and storage of materials (inventory) through the organisation and its marketing channel in such a way that profitability is maximised through cost-effective fulfillment of orders (Stock and Lambert, 2001; Anon, 2003). It forms part of the supply chain process that implements, controls and ensures an effective flow of stored goods, services and related information from the point of origin to the point of consumption (Hugo et al., 2002). 


\subsubsection{Disposal management}

Disposal management is the letting away of assets that are no longer needed, including unserviceable, redundant or obsolete assets. It gives due consideration to obsolescence planning, creation of a database of redundant material, inspecting material for potential re-use, deter-mining a disposal strategy and executing the physical disposal process [Republic of South Africa. 2004]. It is recommended that accounting officers appoint specific committees to deal with disposals, and their recommendations are considered for disposal decisions (MFMA Sections 14 and 90).

\subsubsection{Risk management}

Risk refers to unintended or unexpected outcome of a decision or action. Risk management is the provision of an effective system for identification, consideration and avoidance of potential risks. It includes the identification of risks on a case-by-case, allocation of risks to the party that is best suited to manage it, acceptance of the cost of the risk, the management of risk in a pro-active manner and provision of adequate cover for residual risk as well as the assignment of relative risks to the contracting parties through clear and unambiguous contract documents (SAMDI, 2005).

\subsubsection{Supply chain management performance}

Supply chain performance is a monitoring process under-taking a retrospective analysis to determine whether the proper processes have been followed and whether the desired objectives were achieved. The South African Government's national treasury has developed a reporting template that is used by provincial treasuries to monitor SCM implementation process at the relevant public entities. To continuously improve the supply chain performance, public entities are expected to adopt the template to enhance their supply chain performance (Republic of South Africa. 2005).

\section{Findings and Empirical Analysis}

The findings are presented in three main sections, namely, demographic information, information relating to the training on compliance with SCM legislation and processes; information relating to the various SCM operations and compliance measures, such as public auditing.

\subsection{Demographic profile of respondents}

According to the results from the study, it is illustrated that 37 percent of employees are in the age group 31-40 years, which shows management's preference to employ middle-aged personnel. Research shows that 20 percent of the respondents fall in the over 50-year age group, which is made up mainly of well-experienced personnel, close to retirement. Operations dynamics can become severely disrupted when a senior member of a team leaves the employ. A generic training programme, such as the one offered at the Provincial Treasury, familiarizes every member with all sides of the department, in order to prepare them for placement in new positions, as they may arise within the department. This will also enhance the departmental policy of prioritizing internal placements and promotions.

According to Kooijet al. (2011:3), staff between the ages of 31 to 40 are more flexible in shifting from task to task, and are more technologically advanced, when compared to staff from the over 50 year group. Staff from the over 50-year age group at the department under study, are more disposed to routine work and reluctant to explore new technology. Maurer and Barbeite (2011:4) agree that the decline in the abilities of the over 50 age group is offset by experience and knowledge. The diversity in the age groups enhances operational efficiencies.

\subsection{Highest Educational Level}

According to the study, having a staff profile, where 57 percent of the respondents possess a degree and 30 percent hold a diploma, provides several benefits to the department being researched. According to Monk and Silman (2011:46), "individuals who pursue post-secondary education are perceived to be more ambitious, motivated, self-confident and teachable, than their non-degree associates." This is supported by Nadiadwala (2012:29) who states, "academic qualifications are important because, in order to gain good exam grades or a degree, students have to work hard, master demanding skills and learn a great deal of specialist knowledge".

Training and education levels, according to Karia and Asaari (2006:33), affect the way people think at the 
workplace. A study benefit may be desirable and necessary to motivate staff to acquire knowledge and skills. However, this must be complimented by the overall organizational culture. For the department under research to retain qualified staff it is essential for staff to earn a market related salary according to their level of qualification, otherwise they will only use the study benefit to seek higher salaries and benefits elsewhere. The more qualified an employee becomes, the more measures have to be put in place to retain them. For example, if a job has a high percentage of routine manual labour, it would be unwise to have all graduates in that department.

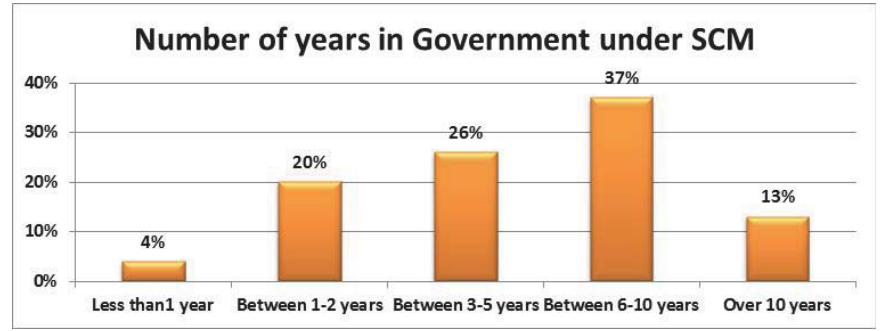

Figure 3. Number of years working for Government under SCM

The results shown on Figure 3 reveal that a collective 37 percent of the respondents have been with the Government in the SCM department for the past six to 10 years and a further 26 percent have been with the Government under the SCM department for the past three to five years. One percent has been with the Government in the SCM department for, or less than, two years. The high percentage of staff staying in Government in the SCM department is indicative of a low staff turnover; due to SCM being a very specialized function, there is consequently no need to replace new vacancies with external recruiting. Furthermore, succession planning should be factored into the human resources strategic planning, to have a cadre of SCM professionals within the Public Sector.

\subsection{Respondents' knowledge of Supply Chain Management}

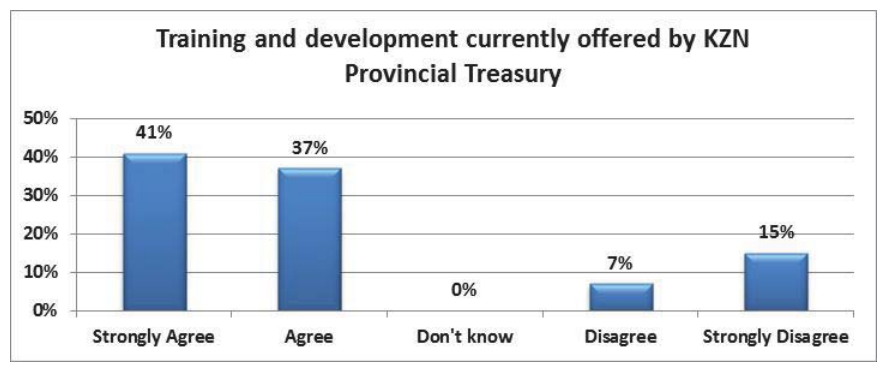

Figure 4. Training and development currently offered by KZN Provincial Treasury

From the results shown in Figure 4, a combined 41 percent of the respondents strongly agreed and 37 percent agreed that the Provincial Treasury provides training. This shows that the training did impact positively on the respondents and they felt it prestigious to be associated with the training. However, 15 percent disagreed that there is training provided by the Provincial Treasury. The 15 percent indicates that the Provincial Treasury SCM Training Unit has to start communicating more and effectively to employees, about the kind of training strategies and training needs the Provincial Treasury does offer.

Employees want to know that their employers recognize their achievements at the workplace. They need to feel appreciated, as workers and as people (Branham, 2005:58). Departments often become focused on community and service delivery, rather than their own employees, who actually drive the service delivery to the communities. In the case of employees, the employees may rarely be praised for the quality of their performance. It may become common for upper management to take the ideas of lower level employees lightly, which leaves employees feeling neglected, and worthless, making it difficult for workers to see a bright future while working for the department. If an employee fails to see 
a bright future with the department, they would have little reason to produce good results. Satisfied workers will work harder for the department and with due recognition for their achievements, they will plan to stay with the department, ultimately reducing departmental labour costs (Gregory, 2011:126).

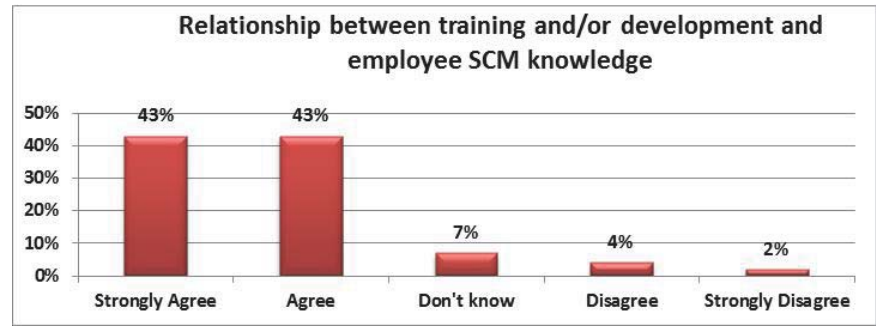

Figure 5. Relationship between training \& development and employee SCM knowledge

From the results shown in Figure 5, 43 percent of the respondents strongly agreed and agreed, that there is a relationship between the training and development and employees' knowledge on SCM. This translates to employees seeing the need for training in SCM, so that they will have sufficient knowledge to implement SCM prescripts. Only two percent strongly disagreed that there is a relationship between the training and development and employees knowledge on SCM; and seven percent don't know.

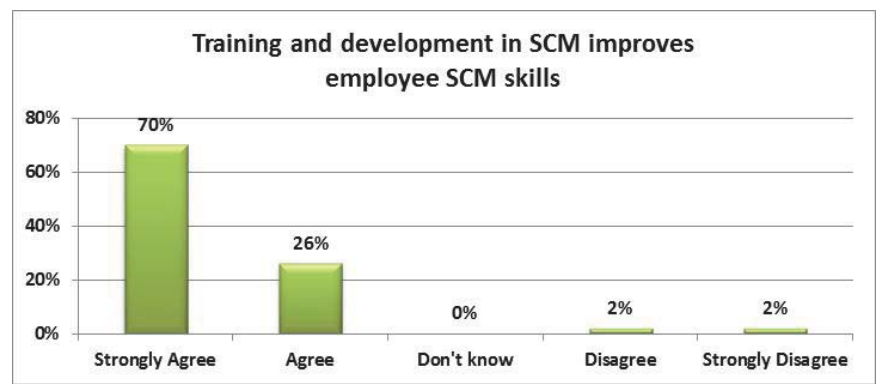

Figure 6. Training and development in SCM improves employee SCM skills

The results, shown in Figure 6, demonstrate that 70 percent of the respondents strongly agreed that there is a relationship between the training and development and employees' skills on SCM, with 26 percent agreeing that there is a relationship between the training and development and employees' skills on SCM. This shows that employees see the need for training in SCM, to have sufficient skills to implement SCM. Only two percent strongly disagreed that there is a relationship between the training and development and employees skills on SCM; and there were no respondents who indicated that they don't know.

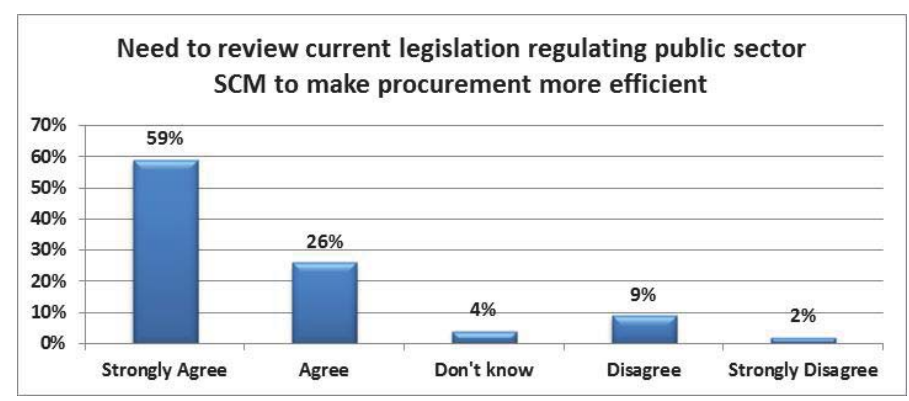

Figure 7. Need to review current legislation regulating public sector SCM to make Procurement more efficient 
Results, shown in Figure 7, illustrate that 59 percent of the respondents strongly agreed and 26 percent also agreed, that there is a need to review the current legislation regulating Public Sector procurement. This implies that the Public Sector procurement legislation does not address the needs of public procurement; there is therefore a great need to review legislation, in order to align it with the current changes in the public need for goods, services, and work, to hasten service delivery to the community at large. However, only nine percent disagreed, with only two percent indicating that they strongly disagreed that there is a need to review current legislation regulating Public Sector procurement; while four percent don't know.

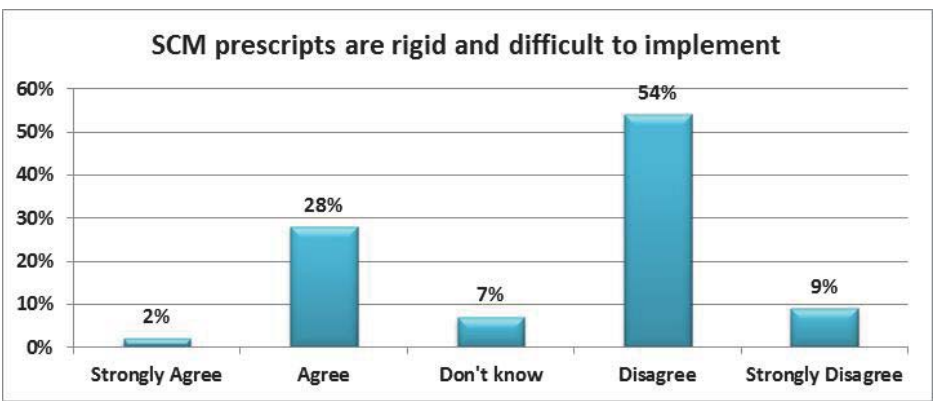

Figure 8. SCM prescripts are rigid and difficult to implement

Figure 8 illustrates that a total of 54 percent of respondents disagreed that SCM prescript are rigid and difficult to implement, however, 28 percent agreed that the SCM prescript are rigid and difficult to implement. The implication is that employees sometimes do know what to do, in order to comply with SCM prescripts, but there might be other external forces, such as political pressure, that compel them to deviate from complying with SCM prescripts. Furthermore, the 28 percent that think SCM prescripts are rigid and difficult to implement indicates that there is a lack of training on SCM prescripts. Only nine percent strongly disagreed that SCM prescript are rigid and difficult to implement, and seven percent don't know.

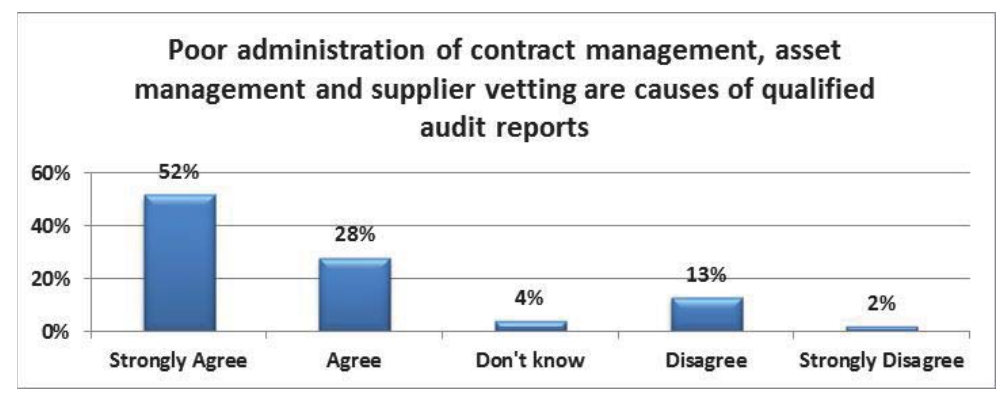

Figure 9. Poor administration of contract management, asset management and supplier vetting are causes of qualified audit reports

From the results shown in Figure 9, a total of 52 percent of respondents strongly agreed that poor administration of contract management, asset management and supplier vetting, are the causes of qualified audit reports, with 28 percent agreeing that poor administration of contract management, asset management and supplier vetting, are the causes of qualified audit reports. This indicates that more targeted training must be conducted for employees who specialize in the administration of contracts, asset management and supplier vetting, including all three bid committee members, which are, Bid Specification Committee (BSC), Bid Evaluation Committee (BEC) and Bid Adjudication Committee (BAC). Only 13 percent disagreed; and four percent don't know. 


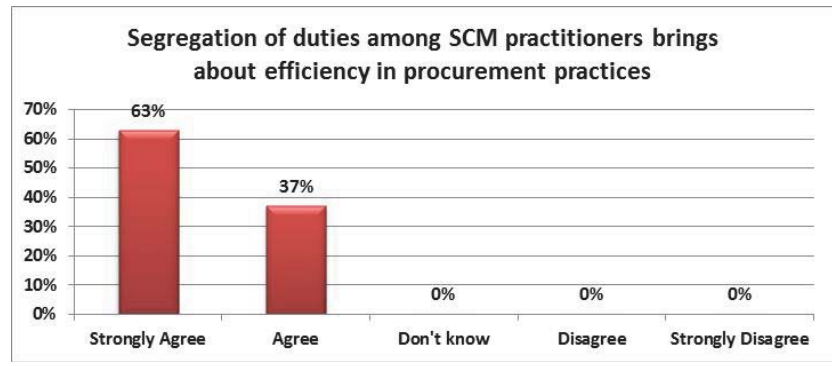

Figure 10. Segregation of duties among SCM practitioners brings about efficiency in procurement practices

As illustrated in the results, shown in Figure 10,63 percent of respondents strongly agreed that the segregation of duties among SCM practitioners brings about efficiency in procurement practices, and 37 percent agreed. Employees therefore thoroughly understand and see the need for segregation of duties as one of the elements to curb fraud and bring about efficiency in SCM operations. The challenge that comes with this good practice, however, is that many public institutions may not have prioritized the filling of vacancies in SCM units.

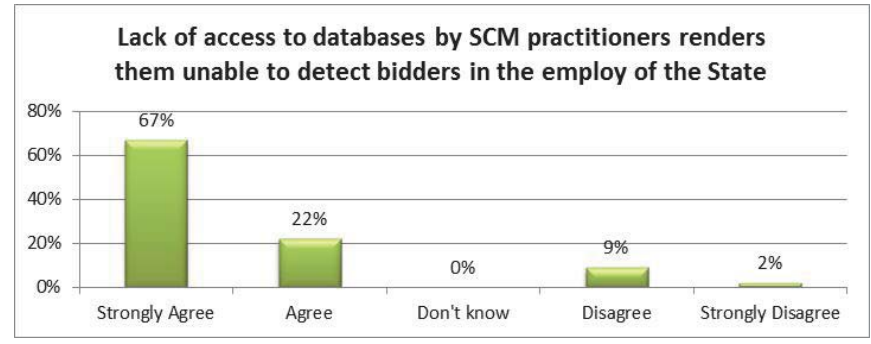

Figure 11. Lack of access to databases by SCM practitioners renders them unable to detect bidders in the employ of the State

Figure 11 illustrates that 67 percent of respondents strongly agree that the lack of access by SCM practitioners to relevant databases, renders SCM practitioners unable to detect service providers in the employ of the State. Twenty-two percent agreed that the lack of access by SCM practitioners to relevant databases renders SCM practitioners unable to detect service providers in the employ of the State. This implies that employees are willing to detect service providers who are in the employ of the State but are unable to do so, because there is no access to databases used by the AuditorGeneral of South Africa, while they are doing their audits. Only nine percent disagreed with the statement.

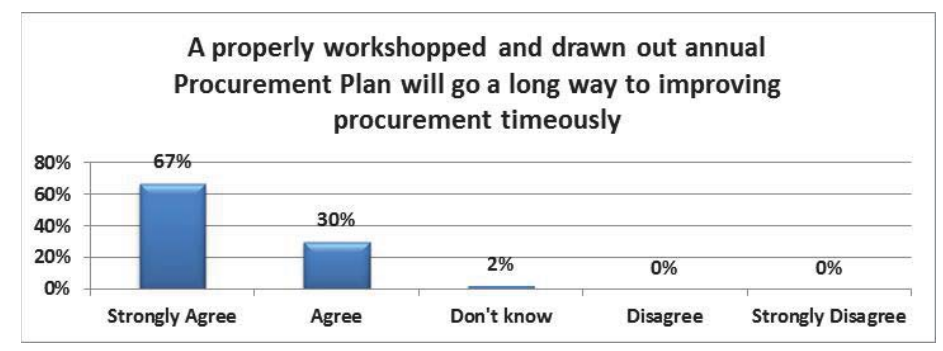

Figure 12. A properly workshopped and drawn out annual Procurement Plan will go a long way to improving procurement timeously

Figure 12 shows that 67 percent of respondents strongly agree that there is a need for a properly drawn and workshopped Annual Procurement Plan, to improve the procurement turnaround time strategy, with 30 percent agreeing 
with the statement. The implication is that there is a great need for the implementation and monitoring of the Annual Procurement Plan, to achieve efficiency in Public Sector procurement.

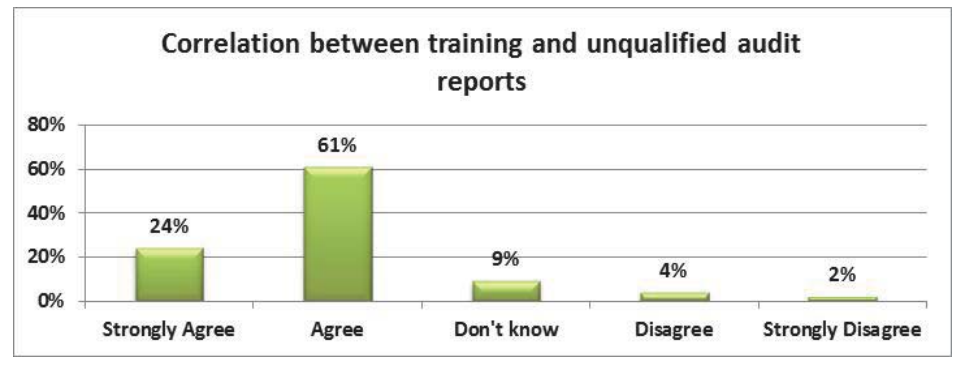

Figure 13. Correlation between training and unqualified audit reports

From the results, shown in Figure 13, a total of 61 percent of respondents strongly agree and 24 percent agree that there is a correlation between training and unqualified audit reports. This shows that employees do see the need to be trained in SCM, so that they will have sufficient skills to implement SCM prescripts. Only two percent strongly disagreed that there is a correlation between training and unqualified audit reports; and nine percent don't know.

\section{Summary and Conclusion}

In conclusion, the study reveals the cause for concern possible causes of the inverse Audit outcomes. This is because the below important issues:

- There is a need for a properly drawn and work-shopped Annual Procurement Plan (APP), to improve procurement turnaround time strategy. This shows a need for the implementation and monitoring of an Annual Procurement Plan, to achieve efficiency in Public Sector procurement conclusion was strongly agreed with by 67 percent of the respondents.

- There is a lack of access by SCM practitioners to the relevant databases, which is rendering SCM practitioners unable to detect service providers in the employ of the State. Employees are therefore willing to detect service providers who are in the employ of the State but there is no access to various and relevant databases and this conclusion was agreed with by 67 percent of the respondents.

- There is a relationship between training and/or development, and employee skills in SCM. This shows that employees recognize the need to be trained in SCM, so that they will have sufficient skills to implement SCM operations and this was strongly agreed upon by 70 percent of the respondents.

\section{Recommendations}

Based on the above findings, it becomes imperative to give the following recommendations:

- It is recommended that management consider building professional networking opportunities, identify opportunities for country-level networking and mentoring, as well as communities of practice related to procurement through supply chain management (SCM); engage existing professional associations (private and public sector) for example CIPS, etc.

- It is also recommended that segregation of duties among SCM practitioners will bring about efficiency in procurement practices. This implies that employees understand and see the need for the segregation of duties, as one of the elements with which to curb fraud and bring about efficiency in SCM operations, this was strongly agreed by 63 percent of the respondents.

- It is further recommended that there must be a review of current legislation that regulates Public Sector procurement. This infers that Public Sector procurement legislation does not address the needs of public procurement ultimately service delivery. A collective 59 percent of the respondents strongly agreed.

- For further research, recommendation would be the replication of the study to other provinces in South Africa to obtain the global view of the situation regarding the implementation of supply chain management best practices which can be shared among various stakeholders. 


\section{References}

Anon. (2003). 'Our Companies, Sainsbury's'. http://www.jsainsbury.co.uk/about/operation_supermarket.htm: Accessed 23 February

Auditor-General of South Africa. (2008) Audit report for 2007/2008 financial year. 1st quarter. South Africa. Auditor-General of South Africa.

Branham, L. (2005) Planning to Become and Employer of Choice. Journal of Organizational Excellence, 24(3): 57-68.

Creswell, J. W. (2009) Research Design: Qualitative, Quantitative, and Mixed Methods Approaches. Thousand Oaks, California: Sage Publications.

Gregory, K. (2011) "The importance of Employee Satisfaction". The Neumann Business Review: Journal of the division of Business and Information Management. Spring 2011 http://www.neumann.edu/academics/divisions (Date accessed: 30 June 2013).

Migiro S .O. and Ambe I. M., (2008) Evaluation of the implementation of public sector supply chain management and challenges: A case study of the central district municipality, North west province, South Africa. African Journal of Business Management Vol.2 (12), pp. 230-242, December 2008. (Date accessed: 30 February 2014).

Hugo WMJ, Badenhorst-Weiss JA, Van Rooyen DC (2002). Purchasing and supply management, 3rd edition. Pretoria: Van Schaik.

Karia N. and Asaari, H. A. H., (2006) The effects of total quality management practices on employees' work-related attitudes, The TQM Magazine, 18(1), 30-43

Kooijet, D., Jansen, P., de Lange, A. and Dikkers, J. (2011) "Age-related factors in the motivation to work: What we know and where we need to go." VU University Amsterdam. Unpublished.

Lewin K (1951). Field Theory in Social Science, Harper Row, London. OGC (2005). Office of Government of Commerce. ': Supply Chain Management in Public Sector procurement: A Guide version: http.www.ogc.gov.uk/documents/scm-final-june05.pdf. Accessed 5 February 2005.

Maurer, T. J. and Barbeite, F. G. (2011) Job Performance and Age. Journal of Organizational Behavior. Issue 32. Pp 248 - 263 (2011) Published online on 4 January 2011 in Wiley online library. http://www.onlinelibrary.wiley.com (Date accessed: 13 July 2013).

Mkhize Z (2004). 'Supply Chain Management Conference: Transforming Government Procurement System', Durban, Republic of South Africa: 22 - 23 November.

Monk, J. and Silman, C. (2011) Active learning in primary classrooms: a case study approach. Harlow: Longman.

Nadiadwala, N. (2012) Academic Qualification Ensures Success in Life. http://www.idebate.org/debatebase/topic_details.phd?topic ID=885 (date accessed: 21 June 2013).

Republic of South Africa. (1999). Public Finance Management Act, 1 of 1999.Pretoria: Government Printers.

Republic of South Africa. (2000). Preferential Procurement Policy Framework Act, 5 of 2000.Pretoria: Government Printers.

Republic of South Africa. (2003). Municipal Finance Management Act, 56 of 2003.Pretoria: Government Printers.

Republic of South Africa. (2003). National Treasury, Policy Strategy to guide uniformity in Procurement reforms processes in government. Pretoria: Government Printers.

Republic of South Africa. (2004) Department of Public Service and Administration: Public-Private Partnership Manua,I 3: 1. http://www.dpsa.gov.za/documents/service_delivery_review/vol3ed1/public\%20private\%20partnerships\%20deliver.pdf: Accessed 23 February, 2006. SAMDI. (2005).

Supply Chain Management: A guide for accounting officers and municipal entities', Course Manual. Pretoria: Government Printers.

Stock JR, Lambert DM (2001). 'Strategic Logistics Management', McGraw-Hill- Irwin.

Stonebraker, Peter and Rasoul Afifi (2004). Toward a Contingency Theory of Supply Chain, Management Decision, 42(9): 1131-1144. 